\title{
Granulocyte changes in infectious mononucleosis
}

\author{
R. L. CARTER ${ }^{1}$ \\ From the Department of Pathology, The Radcliffe Infirmary, Oxford
}

SYNOPSIS Various changes in the granulocytes have been investigated in a large series of patients with infectious mononucleosis. A high proportion of cases regularly show a neutropenia with a shift to the left during the first three to four weeks of the disease; these changes, though transient, may be profound. The band cells present during the acute phase of the disease also show certain alterations in cytochemical staining and low alkaline phosphatase scores are common at this time. The maturation and release of leucocytes from the bone marrow is apparently normal. Theoretical mechanisms for the neutropenia are briefly discussed, including the possible role of excessive peripheral destruction.

The granulocytes in infectious mononucleosis have received relatively little attention: it is usually held that they are often reduced in number and may show a shift to the left, but a recent examination of the literature (Carter, 1965) indicates that both the incidence and extent of such changes differ widely in various accounts and some authors consider that the granulocytes are unaffected. Much of this confusion seems to be due to reporting data from only small series of patients, the use of inadequate criteria for the diagnosis of infectious mononucleosis, and the failure to establish the phase of the disease. It therefore seemed desirable to reassess the whole problem: various qualitative and quantitative changes in the granulocytes have now been investigated in a carefully defined group of cases.

\section{MATERIAL AND METHODS}

One hundred and fifty patients were examined, all of whom had suggestive clinical histories, abnormal blood films and Paul-Bunnell titres of at least 1:80 after absorption with guinea-pig kidney (see Hobson, Lawson, and Wigfield, 1958). A detailed case history was obtained from each patient and all haematological results were recorded according to the phase of the disease, measured in weeks.

Total granulocyte counts were obtained by counting 200 cells in a modified Füchs-Rosenthal counting chamber, using the $4 \mathrm{~mm}$. objective (Hobson et al.. 1958).

The proportion of band and segmented forms was assessed by counting 200 granulocytes in blood smears, stained by the May-Grünwald-Giemsa method, expressing the results as percentages of the band or segmented cells/100 granulocytes. 'Band cells' were taken to

${ }^{1}$ Present address: Department of Pathology, Yale University School of Medicine, New Haven, Connecticut, U.S.A.

Received for publication 28 December 1965. include all young forms between metamyelocytes and segmented cells, and detailed subdivision, e.g., into 'juvenile' and 'stab' forms, was not made. Cells were occasionally encountered which were impossible to classify because of nuclear folding and these were omitted.

Cytochemical staining was examined, using conventional techniques for lipids (Sudan black B method of Sheehan and Storey, 1947); glycogen (P.A.S. method of Hayhoe, Quaglino, and Flemans, 1960); alkaline phosphatase (Azo dye coupling method of Hayhoe and Quaglino, 1958); and peroxidase (Whitby and Britton, 1963). A semi-quantitative system of scoring was used for the alkaline phosphatase preparations, rating individual cells as 0-4 according to the scheme of Hayhoe and Quaglino (1958).

Bone marrow aspirates were obtained from five patients.

\section{RESULTS}

TOTAL GRANULOCYTE COUNTS Figures were available in 211 instances. The range was from 500 to $10,000 / \mathrm{c} . \mathrm{mm}$., and the distribution of counts in relation to the phase of the disease is illustrated in Figure 1.

One hundred and seventy-two counts from the first four weeks of the disease showed the pattern indicated in Table I. Leucopenia was usually moderate but seven cases showed grossly subnormal

\section{TABLE I}

Total Granulocyte Counts

\begin{tabular}{lr}
\hline$<3,000 /$ c.mm. & 109 \\
$3,000-7,500 /$ c.mm. & 62 \\
$>7,500 /$ c.mm. & 1
\end{tabular}




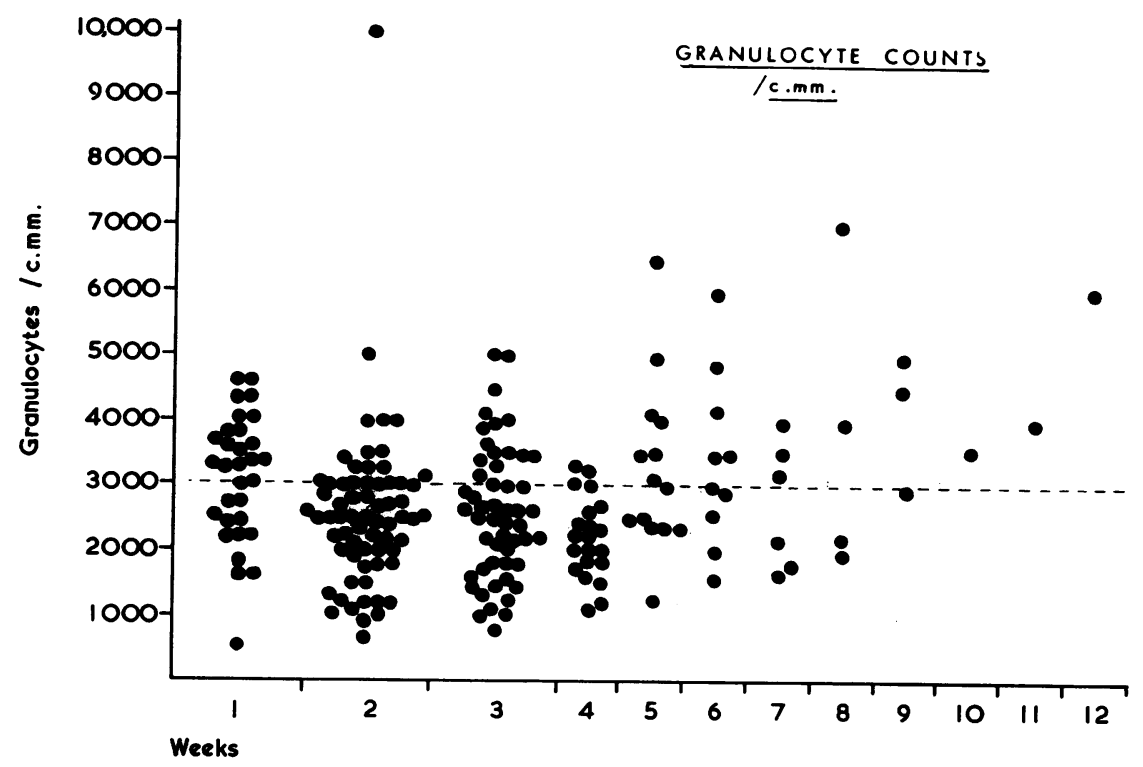

FIG. 1. Distribution of total granulocytew counts, plotted according to the phase of the disease

counts of $1,000 / \mathrm{c} . \mathrm{mm}$. or less. Values began to rise after the fourth week but subnormal figures were still sometimes encountered during convalescence, e.g., as late as the sixth or seventh weeks.

ALTERATIONS IN BAND AND SEGMENTED CELlS A consistent increase in the proportion of band cells was found during the early stages of the disease, often far exceeding the numbers of segmented forms (Fig. 2). Reversion to more normal proportions usually began at about the third week, i.e., before the total granulocyte count began to rise, but an increased proportion of band cells sometimes per sisted up until the fifth, sixth, or seventh weeks.

OBSERVATIONS ON ROMANOWSKY-STAINED FILMS Toxi\& granulation of neutrophils was observed in 12 films and occasional neutrophil myelocytes were seen in nine films.

Eosinophils were normally depressed during the acute phase of the illness. In three cases, a smalp transient eosinophilia was noted in convalescent
FIG. 2. Distribution of band (Fig. 2a) and segmented (Fig. $2 b$ ) granulocytes, plotted according to the phase of the disease.

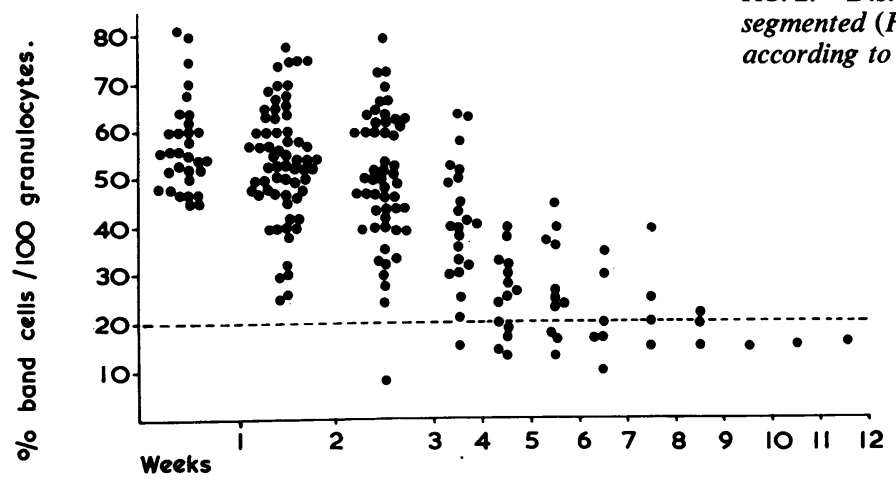

FIG 2a. 


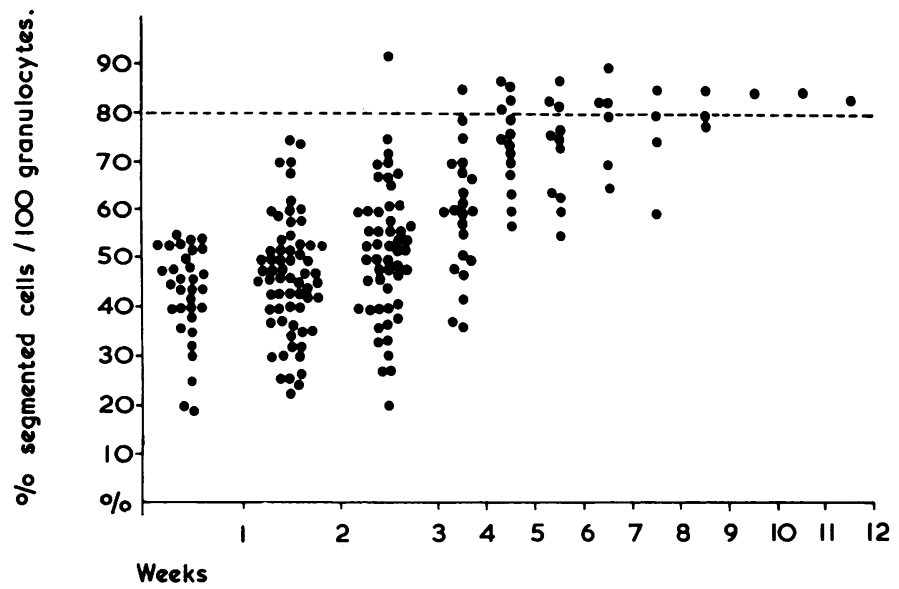

FIG. $2 b$.

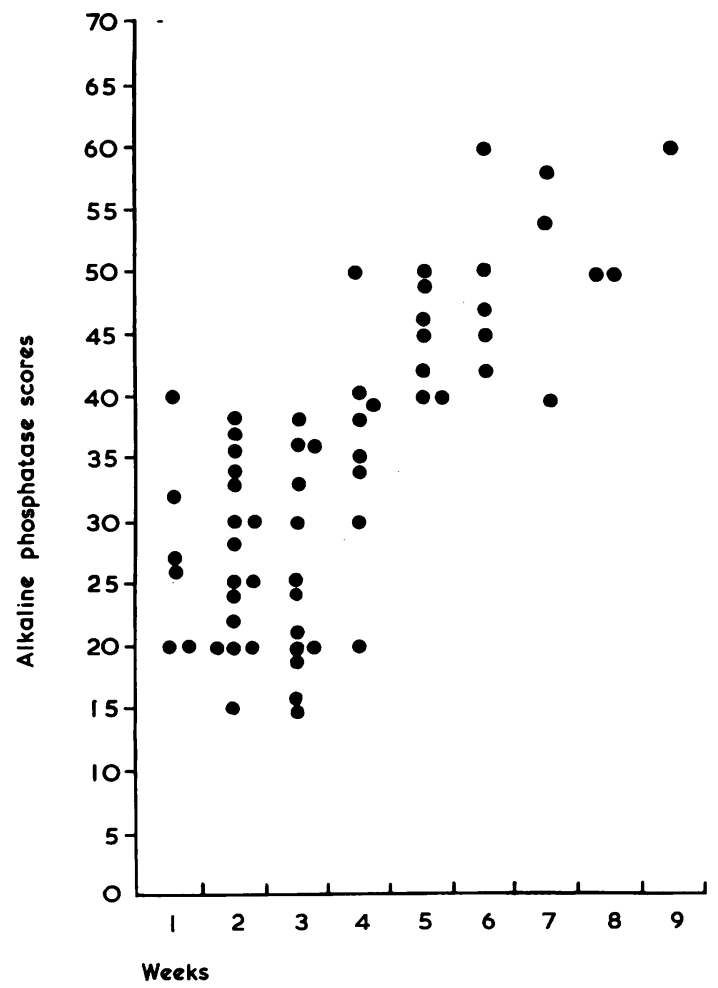

films; none of these patients gave histories of allergic phenomena or of recent exposure to drugs.

Basophils were very occasionally seen.

CYTOCHEMICAL CHANGES The consistent increase in the proportion of band cells during the acute phase of the disease prompted a cytochemical study to see whether the morphological criteria for slight granulocytic immaturity were accompanied by parallel cytochemical changes.

Material from 25 cases was initially studied. It was found that during the acute phase of the disease the band cells showed reduced staining for lipids and for peroxidase; a slight reduction in P.A.S.-positivity; and decreased amounts of alkaline phosphatase often leading to low scores. Further cases were examined for alkaline phosphatase activity and the scores in 60 cases, plotted according to the stage of the disease, are summarized in Fig. 3. Two points emerge; first, scores are often below average during the first three to four weeks but rise thereafter. Secondly, these changes bear a predictable relationship to the alterations in band and segmented cells mentioned earlier. Low scores are found when there is a high proportion of band forms, rising when more segmented cells reappear in the circulation. Alkaline phosphatase staining was also examined in 20 control cases consisting of young adults who were admitted to hospital for minor surgery. The films, made pre-operatively, gave scores in a range of 20 to 62 with an average of 50 .

FIG. 3. Alkaline phosphatase scores in granulocytes.

LEUCOPOIESIS IN BONE MARROW ASPIRATES Samples 
of bone marrow were available for study in five cases; all of them showed active granulocytopoiesis. No abnormal accumulation of granulocyte precursors or of mature cells was noted, the occurrence of which might suggest disturbed maturation or faulty release of cells from the bone marrow.

\section{DISCUSSION}

Granulocyte levels may fluctuate quite widely in healthy individuals and it is difficult to define a definite lower limit of normal; nevertheless, the present findings clearly indicate that neutropenia is a common feature of infectious mononucleosis, particularly during the first four weeks of the disease. Extremely low values may be encountered at this time, occasionally culminating in complete agranulocytosis (Stevens, Bayrd, and Heck, 1952). Normal values are always regained but subnormal counts sometimes persist for another four weeks. No cases with a polymorphonuclear leucocytosis were ever encountered in the present survey and the one patient with the raised granulocyte count of $10,000 /$ c.mm. had a total leucocytosis of 60,00 per c.mm. with a huge excess of atypical mononuclear cells.

Changes in the proportions of band and segmented cells are equally consistent. Although a shift to the left was mentioned by earlier workers (Stuart, Burgess, Lawson, and Wellman, 1934; Foord and Butt, 1939; Downey, 1939) it is now often regarded as a rather inconstant feature seen in a minority of cases (Milne, 1945; Stevens et al., 1952), a view which is not supported by the present findings. It is, however, a short-lasting phenomenon and reversion to normal may on occasion be well advanced when the patient is first seen.

Detailed cytochemical studies on the granulocytes in infectious mononucleosis are presented here for the first time: the pattern of alkaline phosphatase staining is perhaps the most striking finding. Low levels of granulocytic alkaline phosphatase in this disease have also been observed by Hauser and Stroun (1962) but these authors examined fewer cases and did not correlate their findings with the types of granulocytes present or with the phase of the disease. Reduced amounts of granulocytic alkaline phosphatase have also been described in various other acute infections, the viral aetiology of which is undisputed, such as infective hepatitis, rubella, and chickenpox (Hauser and Stroun, 1962)-observations which are in sharp contrast to the increased amounts of enzyme found during many bacterial infections. The reasons for the difference are unknown. The low scores found in the present investigation are also of interest from another standpoint as there is some evidence that the alkaline phosphatasfe content of granulocytes may reflect the age of the cells (Trubowitz, Feldman, Benante, and Hurit. 1958, 1959; Hook and Engel, 1964). Clearly, low levels can be equally characteristic of young cells $\overline{g r}$ senile cells so that correlation with some other $(e . \bar{E}$, morphological) feature of maturity or immaturity $\overline{p_{S}}$ essential. In infectious mononucleosis, the prese data suggest that the granulocytes are probably immature. The significance of decreased amounts $\mathrm{O}$ peroxidase, glycogen, and lipids in leucocytes TS obscure, although by analogy, these also may refleet slight granulocytic immaturity.

Although a neutropenia combined with a shift $\frac{80}{8}$ the left has been demonstrated in most cases during the acute phase of the disease, such changes are nof in themselves, pathognomonic; nor can they be linked with any clinical features of infectious monß nucleosis. No correlation, for example, was established in the present series between the levels of granulocytes and the frequency or severity of orat ulceration (cf. Press, Shlevin, and Rosen, 194\$; Tidy, 1950), and no increased susceptibility generalized secondary infection was observed durigg the neutropenic phase.

Lastly, how does this neutropenia arise? The mechanisms responsible are unknown but two points may be stressed. First, a polymorphonuclear leuc $\bar{q}$ cytosis can undoubtedly occur, either with seconda民్ infection (Bernstein, 1940) or following splenic rup ture (Smith and Custer, 1946); such a response usually sustained, suggesting that there is a genuime increase in granulocyte production rather than redistribution of preformed cells previously sequestered in the tissues or in the bone marrow itself. (No evidence of increased sequestration, e.g., in the spleen has, in fact, ever been recorded in the fetw histological studies which are available.) Second granulocyte precursors in the bone marrow are prob ably not significantly reduced. Most authors describe a leucoblastic hyperplasia with a shift to the left (Limarzi, Paul, and Poncher, 1946; Custer and Smit? 1948; Campbell, 1948) and the five bone marro biopsies examined in the present investigation showef no features suggesting depressed granulocytopoieșis or defective release of cells. Considerations of th kind raise the possibility of excessive periphera destruction, brought about either by the exaggerate activity of the normal destructive processes or abnormal immune mechanisms. Both are almogt entirely speculative but recent observations of leucơagglutinating activity in vitro in some infectio mononucleosis sera (Carter, 1966) may be relevaro. The evaluation of such findings is extremely difficulat but they do at least suggest that immune mechanismos may be implicated in some cases-an entirely reaso 
able view in a disease characterized by a strikingly wide variety of immune responses.

I am indebted to Dr. A. A. Sharp for guidance in the preparation of this paper and to Mrs. D. Hovard and Miss Sheila Crouch for technical assistance.

\section{REFERENCES}

Bernstein, A. (1940). Medicine (Baltimore), 19, 85.

Campbell, A. C. P. (1948). J. Path. Bact., 60, 629.

Carter, R. L. (1965). The Cytology and Immunology of Infectious Mononucleosis D.M. thesis, University of Oxford. (1966), Brit. J. Haemat. 12, 268.

Custer, R. P., and Smith, E. B. (1948). Blood, 3, 830.

Downey, H. (1939). In A Symposium on the Blood and Blood-Forming Organs, p. 194. University of Wisconsin Press, Madison.

Foord, A. G., and Butt, E. M. (1939). Amer. J. clin. Path., 9, 448.
Hauser, E., and Stroun, J. (1962). Schweiz. med. Wschr., 92, 1334.

Hayhoe, F. G. J., and Quaglino, D. (1958). Brit. J. Haemat., 4, 375. , and Flemans, R. J. (1960). Ibid., 6, 23.

Hobson, F. G., Lawson, B., and Wigfield, M. (1958). Brit. med. J., 1,845 .

Hook, E. B., and Engel, R. R. (1964). Lancet, 1, 112.

Limarzi, L. R., Paul, J. T., and Poncher, H. G. (1946). J. Lab. clin. Med., 31, 1079.

Milne, J. (1945). New Engl. J. Med., 233, 727.

Press, J. H., Shlevin, E. L., and Rosen, A. P. (1945). Ann. intern. Med., 22, 546.

Sheehan, H. L., and Storey, G. W. (1947). J. Path. Bact., 59, 336.

Smith, E. B., and Custer, R. P. (1946). Blood, 1, 317.

Stevens, J. E., Bayrd, E. D., and Heck, F. J. (1952). Ibid., 7, 31.

Stuart, C. A., Burgess, A. M., Lawson, H. A., and Wellman, H. E. (1934). Arch. intern. Med., 54, 199.

Tidy, H. L. (1950). Postgrad. med. J., $26,9$.

Trubowitz, S., Feldman, D., Benante, C., and Hunt, V. M. (1958). J. Lab. clin. Med., 52, 259.

,,--- (1959). Amer. J. clin. Path., 31, 483.

Whitby, L. E. H., and Britton, C. J. C. (1963). Disorders of the Blood, 9th ed. Churchill, London.

\section{Reports and Bulletins prepared by the Association of Clinical Biochemists}

The following reports and bulletins are published by the Association of Clinical Biochemists. They may be obtained from Mr. J. T. Ireland, Biochemistry Laboratory, Alder Hey Children's Hospital, Liverpool, 12. The prices include postage, but airmail will be charged extra.

\section{SCIENTIFIC REPORTS}

1 Colorimeters with Flow Through Cells. A Critical Assessment of 4 Instruments. 1965. P. M. G. BROUGHTON and C. RILEY. $13 \mathrm{~s} 6 \mathrm{~d}$.

\section{TECHNICAL BULLETINS}

1 Data Sheet on Control Sera. July 1964. 1s.

2 A Report on the Enzyme Questionnaire Circulated by the Scientific Committee. December 1964. A. H. GOWENLOCK. 1s.

3 Non-recording Spectrophotometers for the Visible and Ultraviolet Ranges. A comparative table of instru- ments available in Great Britain. May 1965. A. H. GOWENLOCK, P. C. NICHOLAS, and J. H. WILKINSON. 1s. 6 d.

4 Control Solutions for Clinical Biochemistry. June 1965. P. M. G. BROUGHTON and A. H. GOWENLOCK. 1s. $6 \mathrm{~d}$.

5 Recording Spectrophotometers. A comparative list of low-priced instruments readily available in Britain. July 1965 . P. SEWELL. 2s. 6d.

6 A guide to Automatic Pipettes. A list of more than 100 instruments compiled from manufacturers' literature. August 1965. P. M. G. BROUGHTON. 5s.

7 Variability Between AutoAnalyzer Modules. August 1965. B. E. NORTHAM 1s 6 d. 